Supplement of Atmos. Chem. Phys., 15, 5501-5519, 2015

http://www.atmos-chem-phys.net/15/5501/2015/

doi:10.5194/acp-15-5501-2015-supplement

(C) Author(s) 2015. CC Attribution 3.0 License.

(c) (i)

Supplement of

\title{
Impacts of emission reductions on aerosol radiative effects
}

\section{J.-P. Pietikäinen et al.}

Correspondence to: J.-P. Pietikäinen (joni-pekka.pietikainen@fmi.fi)

The copyright of individual parts of the supplement might differ from the CC-BY 3.0 licence. 

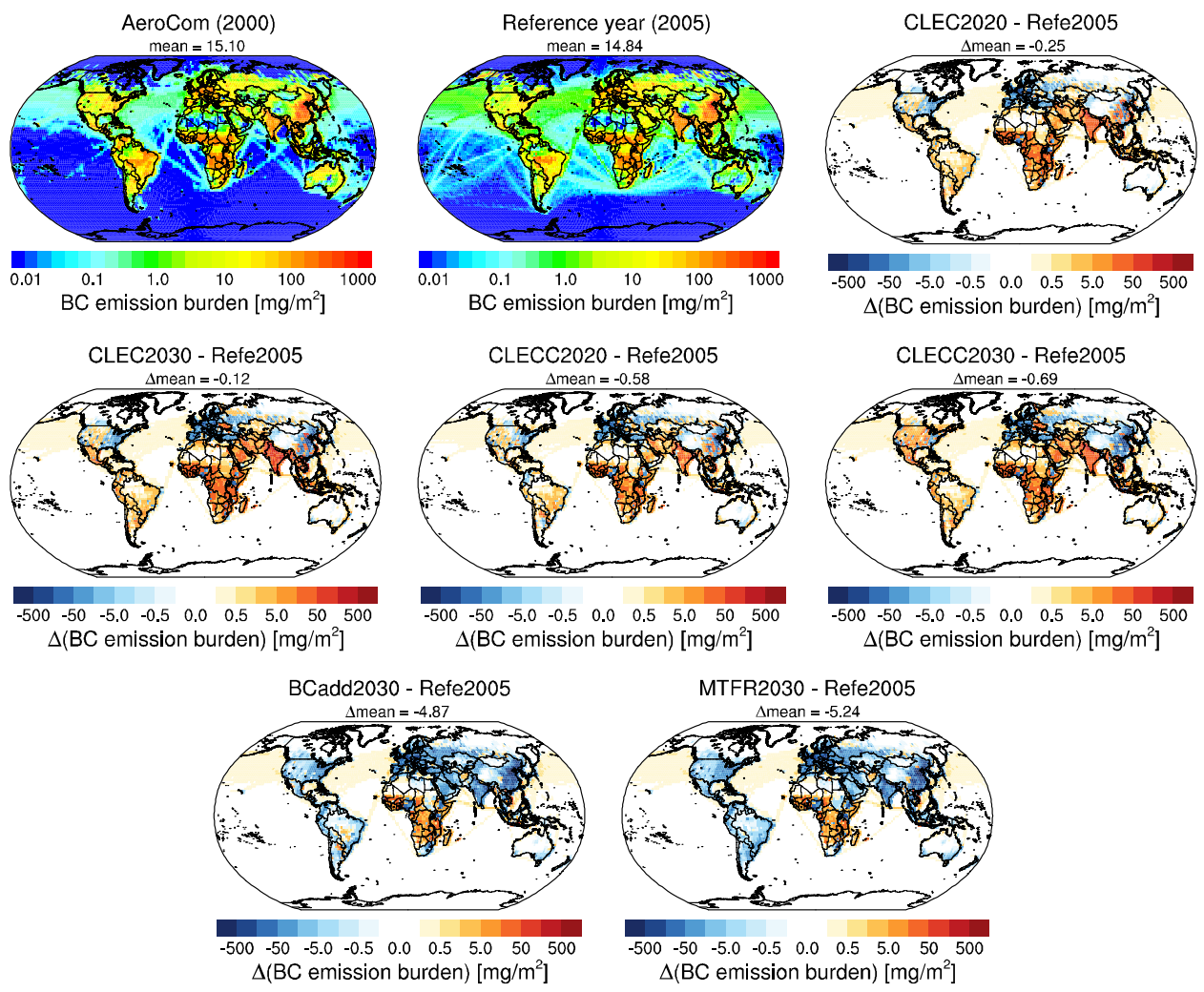

Figure S1: Black carbon (BC) emission burden from AeroCom (2000) and the reference simulation (GAINS 2005). The scenario plots show their differences with respect to the reference simulation. 

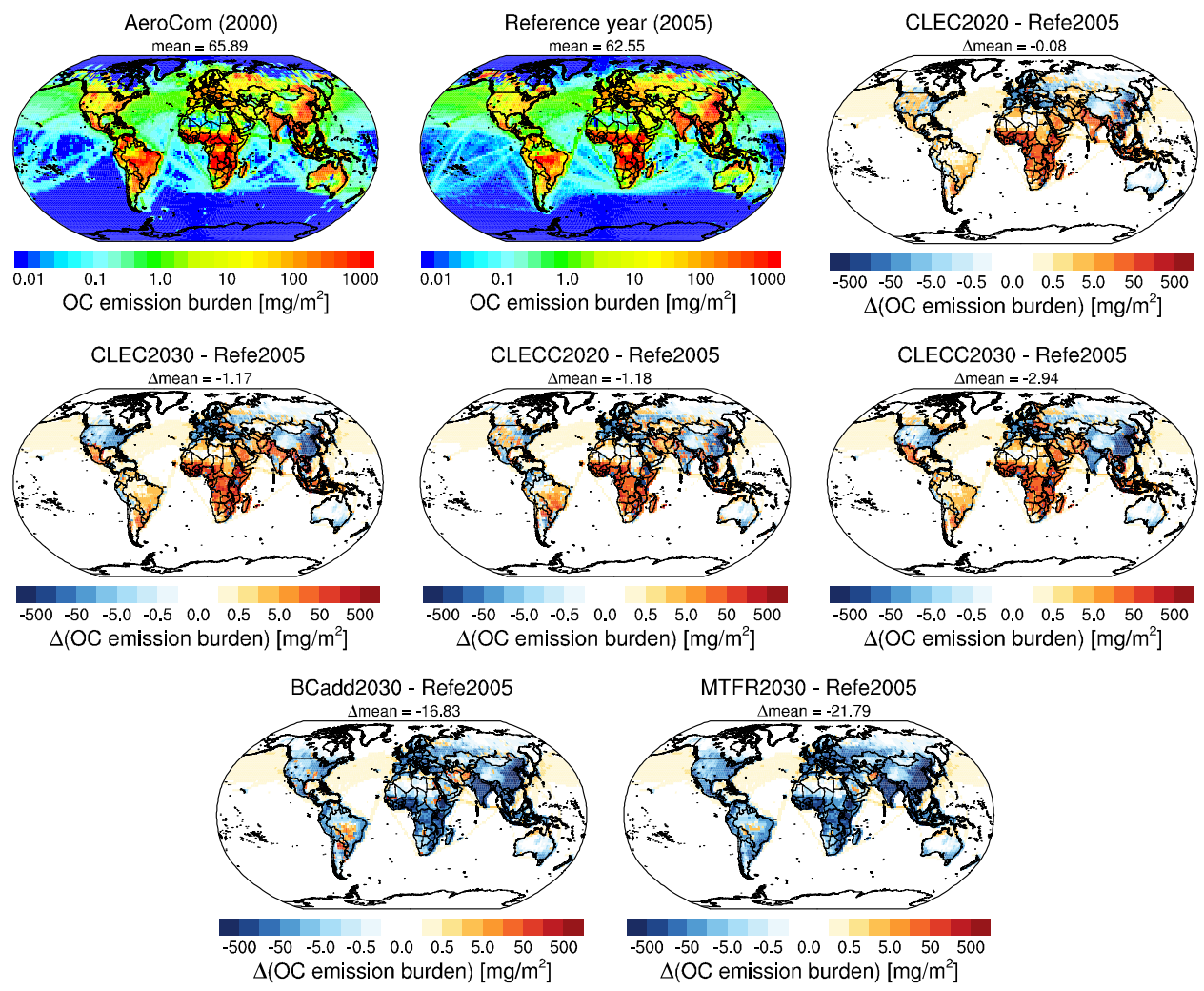

Figure S2: Organic carbon (OC) emission burden from AeroCom (2000) and the reference simulation (GAINS 2005). The scenario plots show their differences with respect to the reference simulation. 


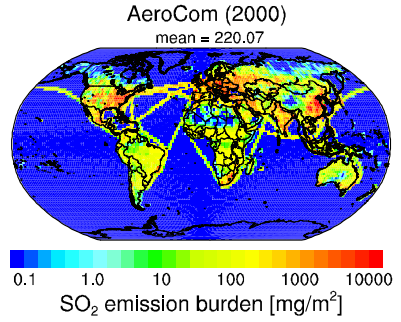

CLEC2030 - Refe2005

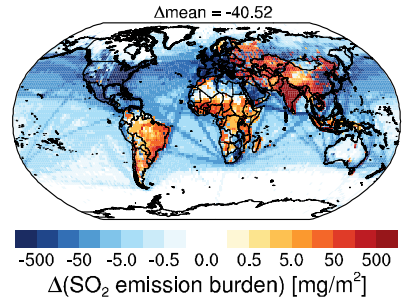

Reference year (2005)

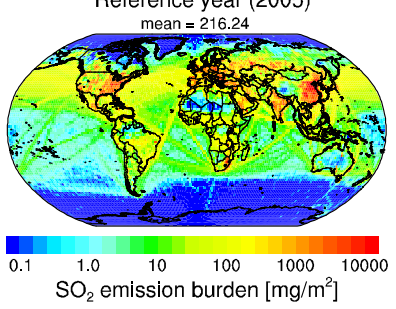

CLECC2020 - Refe2005

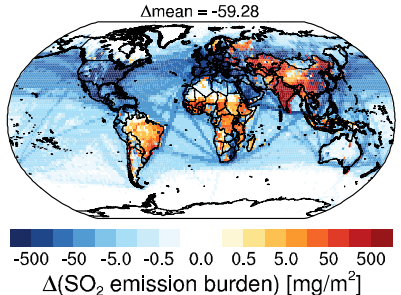

CLEC2020 - Refe2005

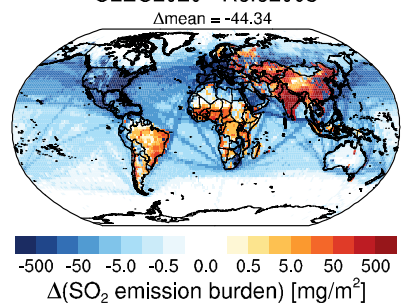

CLECC2030 - Refe2005

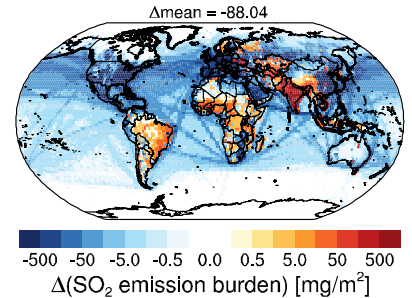

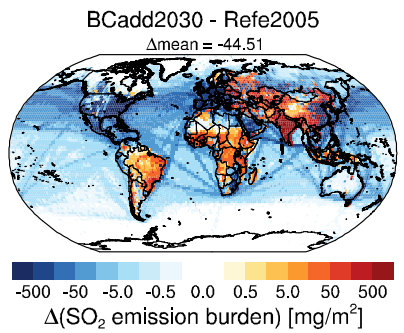

MTFR2030 - Refe2005

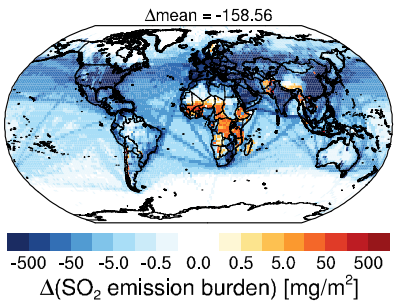

Figure S3: Sulphur dioxide $\left(\mathrm{SO}_{2}\right)$ emission burden from AeroCom (2000) and the reference simulation (GAINS 2005). The scenario plots show their differences with respect to the reference simulation. 


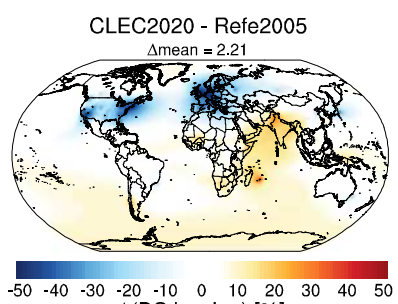

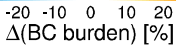

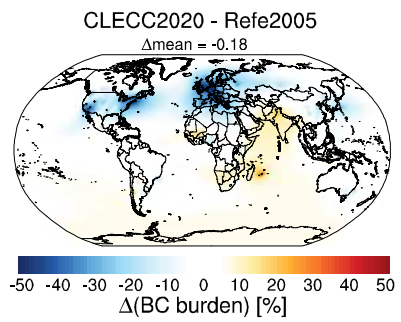

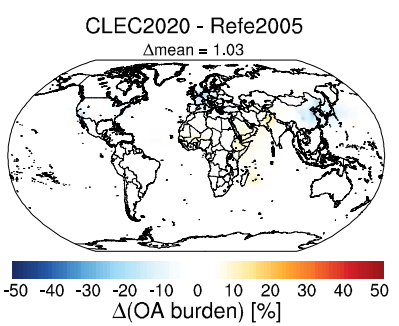

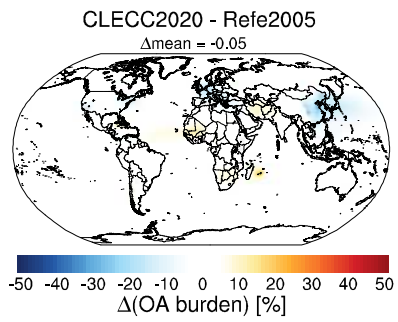

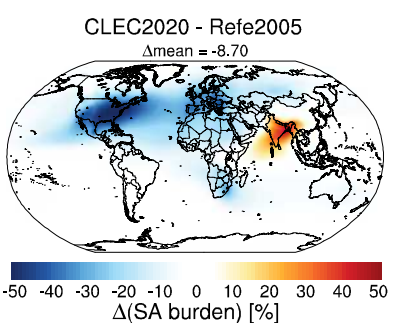

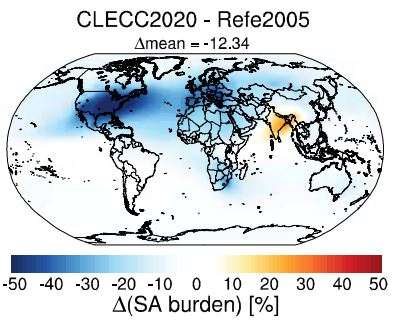

Figure S4: The relative difference of CLEC2020 and CLECC2020 scenarios to the reference run for black carbon (BC), organic aerosol (OA) and sulphate aerosol (SA) burdens. 

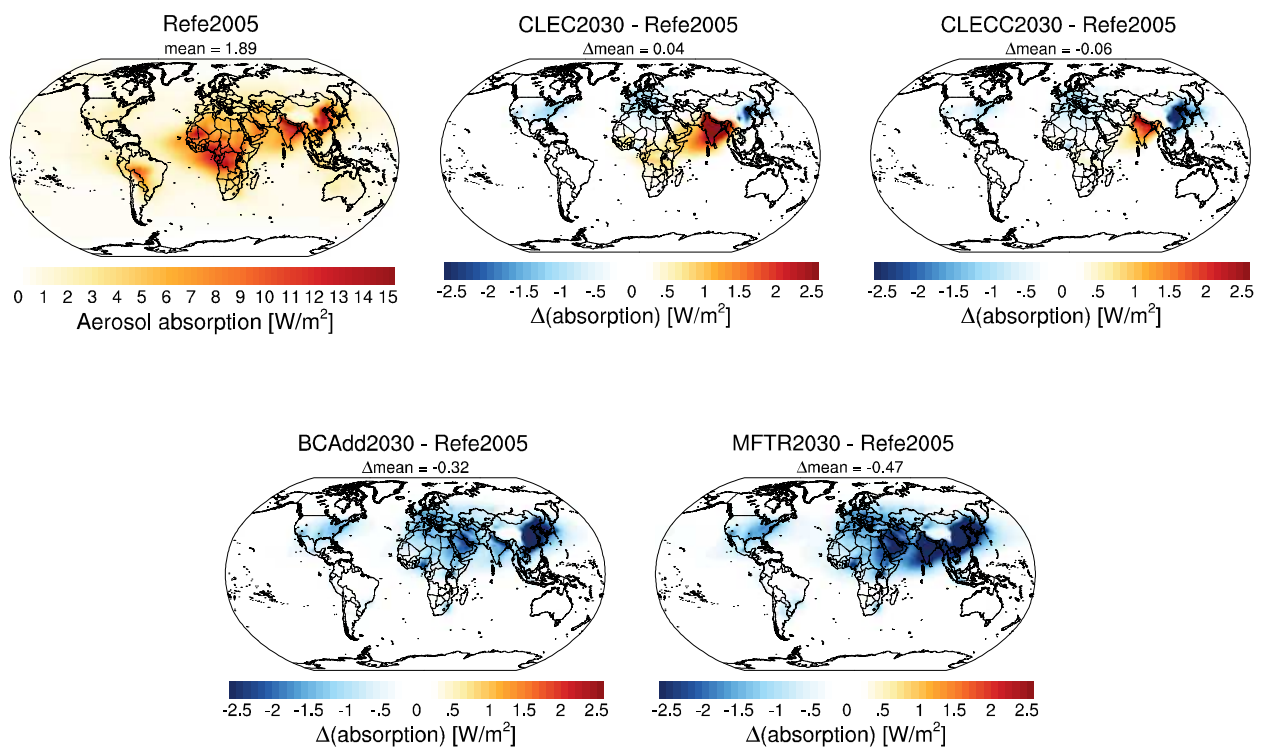

Figure S5: The yearly mean aerosol absorption from the reference run and the difference between scenarios and the reference run. 

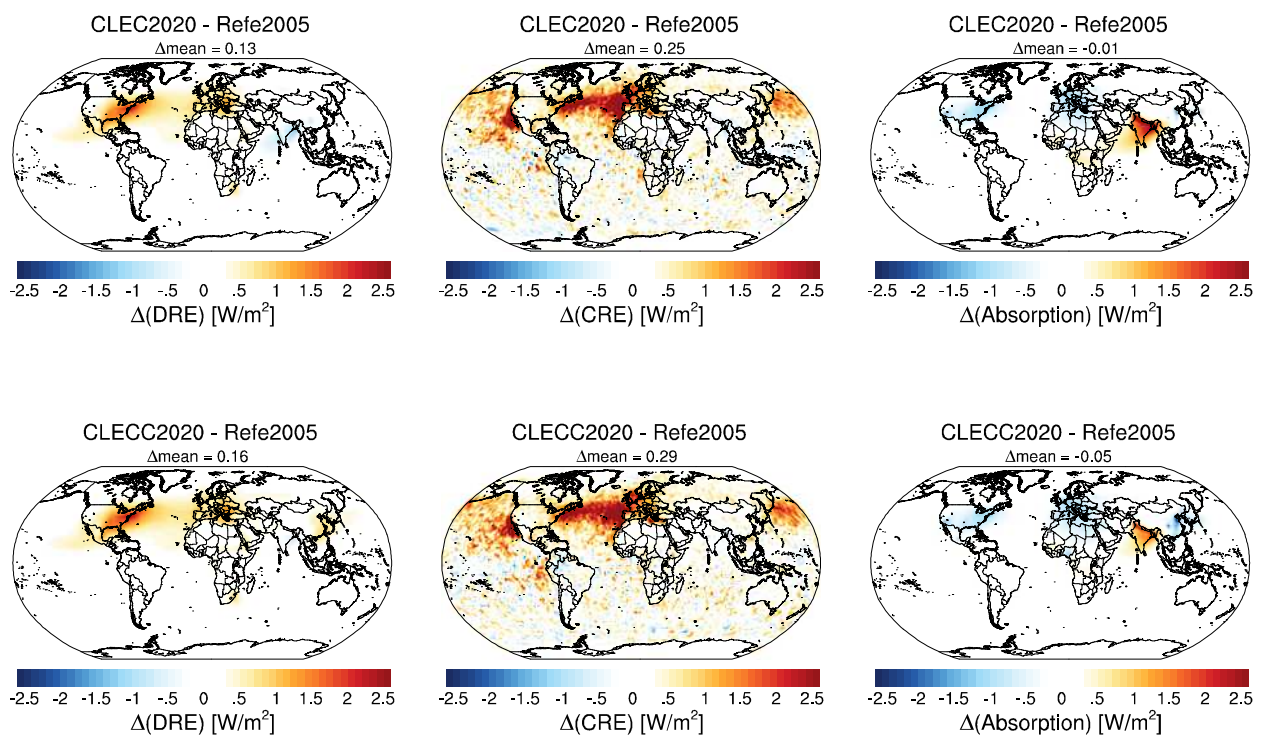

Figure S6: The relative difference of CLEC2020 and CLECC2020 scenarios to the reference run for direct radiative effect (DRE), aerosol absorption and cloud radiative effect (CRE). 